rev.relac.int.estrateg.segur.11(2):271-289,2016

\title{
LA IDENTIDAD ESTRATÉGICA ARGENTINA Y EL ASCENSO DE BRASIL. LAS BASES IDEACIONALES DE UNA POLÍTICA DE DEFENSA COOPERATIVA*
}

\author{
Marina Gisela Vitelli**
}

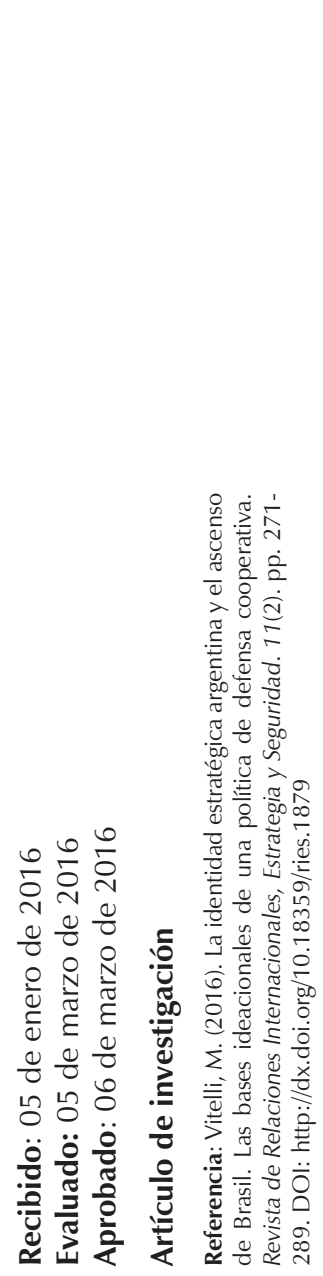

\section{RESUMEN}

En el marco de la reciente discusión académica sobre las respuestas de las potencias secundarias de América del Sur frente al ascenso internacional de Brasil, este trabajo atiende el interrogante ipor qué Argentina no contrabalanceó el creciente poder brasileño? Concretamente, ponemos bajo análisis la participación activa de Argentina en la constitución y actuación del Consejo de Defensa Sudamericano, teniendo en cuenta que este organismo fue interpretado como una iniciativa de construcción del liderazgo regional brasileño en la dimensión estratégico-militar. Argumentamos que la política de defensa cooperativa argentina se explica en virtud de la existencia de un consenso surgido de actores parlamentarios que influyeron sobre la política

\footnotetext{
Este artículo recoge hallazgos de información y análisis que forman parte de nuestra tesis doctoral, defendida en marzo de 2015, en el marco del doctorado en Relaciones Internacionales de la Facultad de Ciencia Política y Relaciones Internacionales de la Universidad Nacional del Rosario, Argentina. La investigación fue financiada por el programa de becas de posgrado del Consejo Nacional de Investigaciones Científicas y Técnicas de Argentina (Conicet), entre 2010 y 2015.

** Doctora en Relaciones Internacionales por la Facultad de Ciencia Política y Relaciones Internacionales (FCPOLIT- RRII) de la Universidad Nacional de Rosario (UNR). Becaria de posdoctorado de la Fapesp en el Programa San Tiago Dantas (UNESP, Unicamp e PUC-SP). Correo electrónico: marinagvitelli@gmail.com
} 
de defensa desde la vuelta de la democracia. Relativizamos, así, aquellos análisis que buscan explicar la ausencia de una estrategia argentina de contrapeso hacia Brasil a partir de variables como la inestabilidad política y la debilidad del sistema de partidos. Para sostener esta hipótesis realizamos un estudio detallado de los actores de la política de defensa argentina democrática, de sus interacciones domésticas y regionales durante el período comprendido en este trabajo, así como las ideas relativas a la defensa nacional y la cooperación regional, variables que trascienden los análisis existentes.

Palabras clave: Argentina, Brasil, congreso, defensa, equilibrio de poderes.

\section{ARGENTINA'S STRATEGIC IDENTITY AND THE BRAZILIAN RISE. THE IDEATIONAL FOUNDATIONS OF A COOPERATIVE DEFENSE POLICY}

\section{ABSTRACT}

In reference to the recent academic debate about the responses of South American secondary powers to the Brazilian rise, this article addresses the question of why Argentina did not counter-balance Brazilian's increasing power. Specifically, we analyze Argentina's active involvement in the creation and functioning of the South American Defense Council, bearing in mind that this organism was considered as part of Brazil's strategy of regional leadership building, in its military-strategic dimension. We argue that Argentina's cooperative defense policy is explained upon the existence of a political consensus, built by parliamentary actors who influenced defense policy from the return of democracy in 1983. In this way, we relativize existent research which tries to explain the absence of an Argentinean counter-balance strategy towards Brazil using variables such as political instability and party system weakness. In order to support our claim, we develop a detailed account of defense politics in democratic Argentina, their interactions, both domestic and regional, as well as their ideas in relation to national defense and cooperation, going beyond existent analyses.

Keywords: Argentina; Brazil; congress; defense; power balance.

\section{A IDENTIDADE ESTRATÉGICA ARGENTINA E A ASCENSÃO DO BRASIL. AS BASES IDEACIONAIS DE UMA POLÍTICA DE DEFESA COOPERATIVA}

\section{RESUMO}

Introduzido no contexto da recente discussão acadêmica sobre as respostas das potências secundárias da América do Sul diante a ascensão brasileira, este trabalho 
enfrenta o interrogante: por que a Argentina não contrabalançou o crescente poder brasileiro? Em concreto, colocamos sob analise a ativa participação da Argentina na constituição e a atividade institucional do Conselho de Defesa SulAmericano, levando em conta que este organismo foi interpretado como uma iniciativa de construção da liderança regional brasileira na dimensão estratégicomilitar. Argumentamos que a política de defesa cooperativa argentina se explica graças à existência de um consenso originado entre personagens parlamentares que foram influentes sobre a política de defesa desde o retorno da democracia. Relativizamos assim, aquelas analises que procuram explicar a ausência de uma estratégia argentina de contrapeso do Brasil, baseadas em variáveis como a instabilidade política e à fraqueza do sistema de partidos. Visando fundamentar a nossa hipótese, fazemos um estudo detalhado dos personagens da política de defesa na Argentina democrática, de suas interações domésticas e regionais dentro do período abrangido neste trabalho, assim como das ideais relativas à defesa nacional e a cooperação regional, variáveis que vão além das análises existentes.

Palavras-chave: Argentina; Brasil; congresso; defesa; equilibrio de poder.

\section{Introducción}

Recientemente ha tenido lugar un muy interesante debate sobre la política suramericana, concretamente sobre el incremento de la posición relativa de Brasil en la región y las reacciones que esta presión subsistémica despertaron en los países vecinos ${ }^{3}$. Concretamente, un grupo de investigadores emprendió el diálogo con ánimo de responder a un interesante interrogante: ¿cómo entender la ausencia de estrategias de contrapeso (balancing) de parte de las potencias secundarias frente al ascenso brasileño?

Si bien pueden identificarse algunas conductas de impugnación del proyecto brasileño de constituirse en el país dominante dentro de la región (por no usar el controvertido concepto de liderazgo), se habría tratado de acciones más vinculadas al concepto de soft-balancing. Estas se caracterizan como estrategias no revisionistas, que en lugar de buscar la reconfiguración del orden regional se

Nos referimos a los artículos publicados en el volumen $52 \mathrm{~N}^{\circ} 2$ de la revista International Politics, por Merke (2015); Flemes \& Whener (2015) y Burges (2015). También incluimos en este debate los trabajos de Schenoni $(2014 ; 2015)$. 
limitan a obstaculizar y constreñir un mayor ascenso de la potencia regional (Flemes \& Wehner, 2015, p. 164). En definitiva, mientras que el realismo prevé ante este tipo de modificaciones de la distribución del poder un patrón general de respuestas de parte de los poderes medios basado en estrategias de contención de ese poder, el panorama suramericano presenta un conjunto importante de casos desviados (deviant-cases), entre estos el argentino. Algunas de las conductas de Argentina no consistentes con los supuestos realistas sobre las dinámicas tendientes a la unipolaridad, según identificaron los participantes del mencionado debate, son el incremento de la interdependencia económica -en lugar de la esperada diversificación de socios económicos- y la persistencia de un bajo gasto militar, indicador de que no se percibió en el ascenso de Brasil una dimensión de riesgo en clave de potencial hegemonía militar.

Frente al desajuste entre la hipótesis neorrealista y la realidad suramericana, parte importante de estos analistas propusieron sumar los aportes realizados por el realismo neoclásico al estudio de las políticas exteriores. Esta teoría complementa el supuesto neorrealista básico el condicionamiento que sobre las conductas de los Estados ejercen las presiones sistémicas determinadas por la distribución del poder en anarquía- con variables intervinientes de naturaleza doméstica. Más específicamente, los casos que se desvían del patrón de conducta esperado por el neorrealismo se explicarían a partir de la inestabilidad política, una variable interviniente conformada por la concentración del poder en el presidente y la baja institucionalización del sistema de partidos. En virtud de este escenario doméstico, la atención de los poderes ejecutivos se desvía de la formulación de la estrategia de política exterior hacia los problemas de política interna (Schenoni, 2014). De no existir esta distracción, estos países se preocuparían más por formular una orientación de política exterior que en el mediano o largo plazo neutralizara la hegemonía brasileña en construcción.

Una Grand Strategy de contrapeso frente a Brasil involucraría tanto la dimensión económica -el modelo de desarrollo no dependiente de este país- como la dimensión de la seguridad y la defensa. Con la excepción de los meses que duró la reticencia colombiana a integrar el Consejo de Defensa Suramericano (CDS) -parcialmente un reflejo de la estrategia brasileña de construcción de su liderazgo regional- la creación de este organismo podría leerse como la confirmación del análisis planteado por esta literatura: al participar con entusiasmo de la propuesta y al no incrementar sus capacidades militares propias, las potencias medias de la subregión no intentaron contrabalancear a Brasil. El caso argentino sería aún más sorprendente: el país mantuvo el bajo gasto militar 
a niveles históricos, y no solo aceptó participar del CDS, sino que además se transformó en uno de los principales promotores de la constitución y consolidación del mismo, planteando proyectos de creciente delegación de su defensa en la instancia regional (Alves Soares \& Camargo Lima, 2013).

Si bien coincidimos con los analistas mencionados en que tal cuestión genera un interrogante interesante sobre las políticas exteriores de las potencias medias, en lo relativo a la posición argentina frente a la redefinición de la dimensión de la defensa regional disentimos al respecto de la explicación dada con base en las variables domésticas señaladas. Pero lejos de plantear la irrelevancia de estas últimas, lo que cuestionamos es la existencia de las mismas en el caso argentino en lo relativo a la formulación de la política de defensa y su vínculo con la cooperación regional desde la vuelta de la democracia. No se trata de discutir que en Argentina la institucionalidad democrática es aún débil y que los presidentes no suelen formular una gran estrategia externa, sino de señalar que en los procesos de definición de la normativa de defensa actual y de las líneas directrices de la política de defensa argentina con fuerte influencia sobre cuestiones de política externa, el Congreso de la Nación tuvo un papel determinante. No solo que la política de defensa fue discutida y formulada en las cámaras del Parlamento: las bases de la misma surgieron de un consenso multipartidario originado en los años ochenta, fortalecido durante los noventa y profundizado durante la primera década del siglo XXI.

Por tanto, argumentamos que la adhesión de Argentina al CDS -y el papel activo desempeñado dentro de él- no es consecuencia de la ideología suramericanista de un gobierno en el marco de una democracia delegativa que desdeña la formulación de una grand strategy. Por el contrario, se trata de una decisión consecuente con un pensamiento sobre defensa nacional y cooperación regional, surgido de la interacción entre actores políticos con anclaje parlamentario, vinculación regional y tradición de reflexión. Estas variables se ven oscurecidas si se aplica al caso el supuesto general de que Argentina es una democracia con inestabilidad política y con una élite dividida, en donde no hay formulación de una estrategia de política exterior. A partir de un estudio detallado de los actores de la política de defensa argentina democrática, de sus interacciones domésticas y regionales y de sus ideas -variables que trascienden los limitados instrumentos de análisis neorrealistas- es posible reconstruir estos procesos.

A continuación, desarrollaremos este argumento en tres apartados. En primer lugar, daremos cuenta de la participación protagónica de actores políticos parlamentarios legisladores y sus asesores- en la definición de la normativa de la 
política de defensa argentina desde el retorno de la democracia, en 1983, haciendo hincapié en dos cuestiones: la articulación de lo que se conoce como el "consenso mínimo" sobre política de defensa surgido del Parlamento, y la descripción del papel de estos actores en el diálogo con la sociedad civil y con los países vecinos. En segundo lugar, analizaremos las ideas sostenidas por esos actores en materia del posicionamiento estratégico del país y el lugar de la cooperación regional en el mismo, relacionando estas creencias con la política argentina hacia la creación del CDS. Para cerrar, discutiremos en la conclusión la relación entre dichas bases ideacionales de la política de defensa cooperativa con la inexistencia de una estrategia de balancing contra Brasil, incluyendo, para finalizar, algunas reflexiones sobre el trasfondo teórico de lo sostenido.

\section{Política de defensa y actores de la democracia}

En la Argentina de 1983 cada dimensión de la vida nacional estaba planteada como un enorme desafío. El país debía reconstruir el sistema político en medio de un escenario de gran fragilidad de la autoridad constitucional, de una economía estancada y endeudada, de un gran desprestigio internacional producto de la Guerra de las Malvinas y de la situación de los derechos humanos, todas cuestiones atravesadas, en mayor o menor medida, por el lugar de las fuerzas armadas en la sociedad y en el sistema político. En el contexto de la tensión abierta por la cuestión militar, parte importante del fortalecimiento de la autoridad constitucional pasaba por reformar la Ley de Defensa Nacional sancionada durante el gobierno de Carlos Onganía, en 1966, materialización normativa de la doctrina de la seguridad nacional. La urgencia y la importancia de esta cuestión no evitaban la existencia de grandes diferencias de criterio, tanto fuera como dentro de los partidos políticos, en particular de los dos mayoritarios: la Unión Cívica Radical (UCR) y el Partido Justicialista (PJ). Dentro de los mismos convivían visiones que se alejaban o acercaban, respectivamente, de dos concepciones que irían a desaparecer: una perspectiva de la defensa como la nación en armas -ligada al peronismo tradicional- y aquella vinculada a la doctrina de la seguridad nacional, asociada a la lucha contra la subversión. Ambas otorgaban a las fuerzas armadas un papel preponderante en la seguridad nacional: la primera para servir al gobierno popular, la segunda como guardianes de los verdaderos intereses de la patria en un contexto de conflicto ideológico global (Ugarte, 2004).

Luego de intentos fallidos por sancionar una ley de defensa nacional, en 1987 la coyuntura política planteada por el levantamiento carapintada de Semana Santa y la derrota del oficialismo en 
las elecciones intermedias resultó propicia para la articulación de un consenso bipartidista entre el Peronismo Renovador y un sector del Radicalismo, en el que también participaron el Partido Intransigente y la Democracia Cristiana. Otros trabajos han reconstruido las frenéticas negociaciones llevadas adelante por los respectivos diputados y senadores con sus respectivos asesores, demostrando que se trató de una activa negociación, precedida incluso por discusiones doctrinarias, tanto en el seno de ambas cámaras del Congreso -en las respectivas Comisiones de Defensacomo en el marco de eventos académicos, como detallaremos más adelante (Druetta, 1989; Laleff Ilieff, 2012; Tibiletti, 1995).

Así, un grupo de diputados encabezado por Miguel Ángel Toma, por el PJ, y Balbino Zubiri, por la UCR, presentaron el proyecto que resultara aprobado en la Cámara de Diputados, luego en el Senado y finalmente sancionado por el Ejecutivo como la Ley 23.554 (Ugarte, 1990, p. 249). El sentido de esta norma fue dar por tierra con la doctrina de la seguridad nacional e instaurar el control civil sobre las fuerzas armadas. En parte importante, esto se estableció con los artículos Nos. 2 y 4 , que circunscriben el ámbito de acción de las fuerzas a las agresiones de origen externo, impidiendo su involucramiento en el combate de enemigos internos ${ }^{4}$. Si bien en ese momento aquella separación estaba pensada para evitar la continuación de acciones contra enemigos políticos domésticos, veremos que en adelante el mismo criterio fue utilizado por estos actores parlamentarios para desactivar cualquier proyecto proveniente de actores militares o políticos -incluso el poder ejecutivo- de involucrar a las fuerzas armadas en el combate contra el crimen organizado y el terrorismo, las denominadas nuevas amenazas.

Más adelante, ya durante el gobierno de Carlos Menem, pero continuando con la misma lógica de trabajo, fueron aprobadas las otras leyes que completarían la normativa de la defensa nacional: la Ley 24.059 de Seguridad Interior (18 diciembre de 1991), la Ley 24.429 de Servicio Militar Voluntario (14 diciembre de 1994), la ILy 24.948 de Reestructuración de las

\footnotetext{
El artículo № 2 de la Ley 23.554 establece: “La defensa nacional es la integración y la acción coordinada de todas las fuerzas de la Nación para la solución de aquellos conflictos que requieran el empleo de las Fuerzas Armadas, en forma disuasiva o efectiva para enfrentar las agresiones de origen externo". Por su parte, el artículo $\mathrm{N}^{\circ} 4$ insiste en que "Para dilucidar las cuestiones atinentes a la defensa nacional, se deberá tener permanentemente en cuenta la diferencia fundamental que separa a la defensa nacional de la seguridad interior. La seguridad interior será regida por una ley especial". Resulta interesante subrayar, como aclara Ugarte, que la Ley de Defensa Nacional omitió de forma adrede una definición de Seguridad Nacional, concepto que actuaba tanto en la concepción del sector conservador del peronismo como en la de la DSN como el pretexto para colocar todas las dimensiones de la vida nacional bajo la potencial intervención de las fuerzas armadas (Ugarte, 2004, p. 205).
} 
Fuerzas Armadas (18 de febrero de 1998) y la Ley 25.520 de Inteligencia Nacional (27 de noviembre de 2001) . A pesar del cambio de signo político, durante los años noventa el Congreso continuó siendo el lugar de la discusión sobre política de defensa, tanto en la dimensión doméstica de esta relación -sentando las bases normativas del control civil- como en lo relativo a su dimensión internacional: el modelo de defensa y la relación con otros países.

El Congreso no solo funcionó como ámbito privilegiado de discusión y negociación partidaria, en el que se formuló la nueva normativa de defensa, sino también operó como un actor clave del debate académico y la vinculación con la sociedad civil. La vuelta de la democracia permitió un aumento del interés académico por un tema que hasta entonces había sido coto vedado de los militares y un gran tabú para los académicos civiles. Los seminarios y jornadas sobre las cuestiones militares en la democracia se multiplicaron, contando con la participación tanto de los think tanks partidarios como de instituciones académicas y de la sociedad civil ${ }^{6}$. Protagonizaban los debates el Centro de Estudios para el Proyecto Nacional del PJ (Cepna), la Fundación Arturo Illia para la Democracia y la Paz de la UCR (FAI), la Escuela de Sociología de la Universidad de Buenos Aires (UBA), el Centro de Estudios para la Nueva Mayoría y la Facultad Latinoamericana de Ciencias Sociales (Flacso), en particular el área Fuerzas Armadas y Sociedad coordinada por Ernesto López, quien luego dirigiera el Programa de Investigaciones sobre Fuerzas Armadas y Sociedad (Pifas) de la Universidad Nacional de Quilmes ${ }^{7}$.

Pero el protagonismo del Congreso en la articulación del debate sobre defensa nacional con la sociedad civil tuvo su mayor indicador en la realización del Seminario Permanente hacia las Fuerzas

Cabe destacar también la realización en 1995 del Ciclo de Audiencias Públicas sobre Defensa Nacional, bajo el auspicio de ambas cámaras del Congreso. Durante diecinueve encuentros celebrados entre agosto y noviembre de 1995 se discutió sobre la restructuración, el tamaño y la modernización de las fuerzas armadas argentinas, así como respecto al ambiente estratégico y la seguridad cooperativa, entre otros temas. Otro antecedente del papel activo cumplido por el Congreso fue la resolución emitida por el Senado, el 7 de marzo de 1996, instando al Ejecutivo a comprometerse activamente con la formulación de una Directiva Estratégica Nacional y un plan de reformas (Martínez, 2000).

6 Junto con la actividad parlamentaria, ambos partidos políticos fueron constituyendo como parte de sus estructuras permanentes oficinas destinadas a la reflexión sobre la cuestión militar y la defensa nacional (Miguens, Druetta, y Tibiletti, 1994, p. 223).

7 Entre los principales eventos organizados cabe mencionar el Seminario sobre "Sociedades democráticas y sociedades militaristas" realizado en 1984 y la Conferencia sobre Fuerzas Armadas, Estado, Defensa y Sociedad, en octubre de 1988, cuyos trabajos fueron publicados en el libro Defensa y democracia: un debate entre civiles y militares ( Druetta, Estevez, López \& Miguens, 1990). Los eventos realizados en este marco contaron con la presencia tanto de parlamentarios como de sus asesores, quienes se convirtieron en expertos de referencia en la temática (Soprano, 2012). 
Armadas del año 2000. El mismo surgió como idea del senador Eduardo Vaca (PJ) en 1990, realizando hasta 1997 un total de 65 encuentros sobre temas de política de defensa. Al término de los seminarios, entre 1998 y 2004, el grupo de expertos que había surgido del Congreso y luego conformado organizaciones de la sociedad civil -Como SER en el 2000- o se había insertado en instituciones académicas, organizaron las siete ediciones de los Encuentros Nacionales de Estudios Estratégicos entre 1998 y 2004 (Vitelli, 2015).

Tanto el programa del Seminario como el de los Encuentros incluían una gran diversidad de temas, como la situación nacional, regional e internacional; las alternativas de inserción económica internacional y los modelos de desarrollo; la política de defensa nacional, su repercusión sobre las tres fuerzas y las relaciones cívico-militares; los esquemas de seguridad colectiva y alianzas regionales; los conceptos estratégicos, como la disuasión y la suficiencia defensiva; los procesos de integración regional, las operaciones de paz y los procesos de reforma y restructuración de las fuerzas armadas (Scheetz, 1994; Diamint, 1997; Tibiletti, 2001). Esto es: no se hablaba solo de cuestiones militares sino de la orientación general de la política de defensa y la relación de esta con la política exterior.

Sobre esto último, la década de los noventa también se caracterizó por una participación activa de la Cancillería en algunos temas de defensa, e incluso en la participación de funcionarios del Palacio San Martín en el Edificio Libertador. Puede pensarse entonces que la actuación del Congreso estaba subordinada a los designios presidenciales canalizados por una Cancillería orientada por el alineamiento con Estados Unidos, pero no fue así. En su lugar, lo que ocurrió fue una pugna entre ambos actores: el Congreso y la Cancillería trabajaban juntos en los temas que coincidían, como la cooperación regional y los procesos de construcción de confianza con los vecinos. Por el contrario, en aquellos temas en los que disentían, como el intento de acercamiento a la OTAN o en las presiones de Estados Unidos por que Argentina aceptara la transformación doctrinaria de involucrar a los militares en la lucha contra las nuevas amenazas, los actores parlamentarios sostuvieron su oposición. Esta dinámica de acercamiento y diferenciación constituye un claro indicador de que la Policía de defensa argentina durante el período consignado no puede explicarse a partir de la democracia delegativa y el súper presidencialismo.

Tal fue la relevancia de estos actores con anclaje parlamentario en la formulación de la política de defensa que no sería exagerado sostener que constituyeron importantes agentes de construcción de la cooperación regional en defensa, antecedente fundamental de la creación del 
CDS. Indicador de este papel fue la participación regular en el Seminario de actores relevantes de las políticas de defensa de países vecinos. Ideado en el marco de la Comisión de Defensa del Senado y luego continuado por la asociación SER en el 2000-conformada fundamentalmente por asesores de los parlamentarios y presidida en un comienzo por el senador Vaca- el Seminario regularmente invitaba en calidad de disertantes y participantes a funcionarios de defensa y miembros de las fuerzas armadas de los países vecinos, en particular Brasily Chile, pero también de Estados Unidos, Francia, España. De igual manera, participaban expertos de la región, provenientes de instituciones como Flacso Chile, el Núcleo de Estudios Estratégicos de la Universidad de Campinas (NEEUnicamp), el Instituto Brasileiro de Assuntos Estratégicos (IBAE) y el Centro de Estudios Estratégicos de la Secretaría de Asuntos Estratégicos de la Presidencia (CEE-SAE), entre muchos otros ${ }^{8}$. Con estas últimas dos instituciones, SER en el 2000 mantuvo varias reuniones en las que se discutió, entre otros temas, las perspectivas de institucionalizar la cooperación en defensa entre los países del Cono Sur ${ }^{9}$ (Castro, 2010). Por su parte, la relación entre estos actores parlamentarios y
Flacso Chile resultó fundamental para la construcción, en 1995, del Comité Permanente de Seguridad entre Chile y Argentina (Comperseg), el esquema de diálogo bilateral en materia de cooperación en defensa (García \& Tibiletti, 2008).

La influencia de estos actores sobrevivió a un nuevo cambio de gobierno. Si bien el primer ministro de Defensa de Néstor Kirchner, José Pampuro, no llevó adelante una gestión particularmente relevante, cabe subrayar que sumó a la plana de secretarios y directores de la cartera a algunos de los asesores parlamentarios que habían sido muy activos durante las décadas anteriore $^{10}$. Con la llegada de la ministra Nilda Garré, en diciembre de 2005, la cartera de Defensa fortaleció su autoridad política, iniciando tareas de gran impacto doméstico -como la reforma de la Justicia Militar- pero también en términos de planeamiento y de relaciones internacionales (Saín, 2010; Derghougassian, 2012). A efectos de este análisis, y también en términos generales, una de las principales medidas que demuestra la voluntad política de dar cuerpo a la política de defensa fue la emisión, en junio de 2006 del Decreto 727 reglamentario de la Ley de Defensa,

\footnotetext{
8 Miembros de SER en el 2000 solían estar invitados a presentar ponencias en los Encontros Nacionais de Estudos Estratégicos, organizados por la SAE.

$9 \quad$ Entre 1992 y 1995 SER en el 2000 y el IBAE realizaron cuatro reuniones de trabajo, dos en San Pablo y dos en Buenos Aires, hasta la disolución de este instituto (Garreta, 1995).

10 Entre ellos cabe mencionar a Jaime Garreta, Rut Diamint, José Vázquez Ocampo y Ernesto López.
} 
dieciocho años después de su sanción en el Congreso ${ }^{11}$.

Este hecho es indicativo de dos cuestiones. Por un lado, demuestra que el centro dinámico de la política de defensa argentina había pasado del Congreso al Ministerio (Soprano, 2013). Pero lejos de significar un cambio radical de política, el hecho de que el decreto respetara a rajatabla el espíritu de la ley, constituye un indicador de que aquel consenso al que llegaron un conjunto de actores políticos se consolidó como política oficial $^{12}$. Es, precisamente, en las ideas subyacentes a ese consenso donde debe buscarse el origen las condiciones de posibilidad- de la ausencia de una estrategia de contrabalanceo al proyecto brasileño de creación del $\mathrm{CDS}^{13}$.

\section{Las bases ideacionales de la participación argentina en el CDS}

11 Luego de la reglamentación de la ley de defensa siguieron una serie de decretos cuyo propósito era continuar con las definiciones políticas sobre la defensa nacional. Entre ellos, el №169, a través del cual fue aprobada la Directiva sobre "Organización y Funcionamiento de las Fuerzas Armadas", documento que al igual que la reglamentación de la Ley 23.554 había sido formulado por el Ministerio de Defensa. También el Decreto 1714/2009, que aprobaba la Directiva de Política de Defensa Nacional como el documento político de más alto nivel sobre defensa nacional, que fuera actualizada en diciembre de 2014.

12 En un reciente artículo, Verbitsky (2015) menciona que pocos meses atrás el exministro Horacio Jaunarena reconoció que nunca reglamentó la ley mientras ocupó la cartera porque no estaba de acuerdo con su letra.

13 Ciertamente, la reacción positiva de Argentina frente a la creación del CDS encuentra fundamentos en iniciativas de diálogo y cooperación con Brasil en temas de defensa que no necesariamente fueron protagonizadas por los actores con anclaje parlamentario aquí analizados. Se destacan entre las múltiples instancias de interacción entre miembros de las fuerzas armadas de ambos países los "Simposios de Estudios Estratégicos de los Estados Mayores de Argentina y Brasil", encuentros anuales realizados entre 1987 y 1992, en los cuales funcionarios militares -aunque también los hubo civiles- se reunían para presentar ponencias relacionadas con temas de defensa, iniciativa a la cual luego se sumaron Chile, Uruguay y Paraguay. Asimismo, tanto los Ejércitos, las Fuerzas Armadas como las Marinas (incluso antes de 1983) de Argentina y Brasil realizan regularmente ejercicios combinados e intercambian estudiantes en los cursos de altos estudios militares. De igual manera, cabe recordar que a mediados de los noventa, ambos países pusieron en marcha un Mecanismo Permanente de Consulta y Coordinación para el fortalecimiento de las relaciones bilaterales en materia de defensa y seguridad internacional, y en 2000 crearon el Grupo de Trabajo Bilateral de Defensa Brasil-Argentina. Finalmente, un análisis de la aproximación en materia de temas de relevancia estratégica entre ambos países no puede soslayar la experiencia de construcción de confianza y transparencia en materia nuclear, que dio lugar a la creación de la Agencia BrasileñoArgentina de Contabilidad y Control de Materiales Nucleares (ABACC) en 1991. Agradecemos a un evaluador anónimo, quien señaló la conveniencia de mencionar iniciativas sumamente relevantes para el diálogo mutuo sobre defensa por fuera de la actuación de los actores puestos de relieve en este trabajo. 
-entre ellos el propio presidente de la nación-como militares, y que fue resistida por este grupo desde los espacios gubernamentales y de la sociedad civil que les tocara ocupar ${ }^{14}$. La mayoría de los análisis coinciden en señalar que la gestión de Nilda Garré abrió un proceso que plasmó dicho consenso en documentos políticos con impactos sobre el planeamiento militar, comenzando con el decreto reglamentario de la Ley de Defensa Nacional. Ya en sus considerandos el decreto citaba la Resolución 3314 de Naciones Unidas sobre el concepto de agresión, entendida como aquellas perpetradas por fuerzas armadas de otro Estado, excluyendo lo relativo a la seguridad interior, rechazando expresamente la utilización del instrumento militar para combatir las nuevas amenazas. Luego, el artículo $1^{\circ}$ estableció -sin dejar lugar a dudasque "Se entenderá como 'agresión de origen externo' el uso de la fuerza armada por un Estado contra la soberanía, la integridad territorial o la independencia política de nuestro país, o en cualquier otra forma que sea incompatible con la Carta de las Naciones Unidas".

La estricta separación entre seguridad y defensa fue uno de los dos pilares de la política de defensa democrática, siendo la segunda la adopción de un posicionamiento estratégico defensivo, esto es, de explícita renuncia a la proyección de poder mediante el instrumento militar, de compromiso con la resolución pacífica de los conflictos pendientes con países limítrofes, de renuncia a la competencia por la influencia política en la región que pudiera desestabilizar los incipientes procesos de integración y el aporte a la seguridad internacional, garantizando la previsibilidad de la política de defensa argentina (Vitelli, 2011). Parte de esta opción por renunciar a una política de defensa fuerte tuvo que ver con la necesidad de construir poder sobre las fuerzas armadas, achicando su presupuesto y sus ámbitos de actuación. Parte también tuvo que ver con la derrota en Malvinas y la manera en que este conflicto desenmascaró la realidad de las lealtades que los compromisos hemisféricos ocultaban. Así, el complemento de la creencia normativa en que los militares no debían tener hipótesis de empleo sobre enemigos no estatales internos o externos fue otra importante creencia en la pérdida de sentido de las hipótesis de conflicto con los vecinos. Más aun, en un contexto de democracia y ocaso de la Guerra Fría, se imponía la necesidad de pensar la defensa en forma cooperativa, percepción que se planteó ya en la Ley 23.554 con el concepto de hipótesis de confluencia,

\footnotetext{
14 Marcelo Saín (2010) documentó los reiterados intentos de borrar la diferenciación entre la defensa externa y la seguridad interior ocurridos durante los gobiernos de Alfonsín, Menem, De la Rúa y Duahalde.
} 
así como en las iniciativas de diálogo con Brasil y Chile, mencionadas en el apartado anterior.

La creencia en la necesidad de superar las desconfianzas, como parte del esfuerzo por evitar que las fuerzas armadas operaran como actor político, encontró reflejo en las discusiones protagonizadas por expertos europeos y norteamericanos sobre suficiencia defensiva y seguridad cooperativa (Vitelli, 2015). Esas conceptualizaciones, surgidas durante el período de distensión internacional y retomadas en los últimos años del conflicto Este-Oeste para articular su finalización, fueron adaptadas por los actores mencionados a la realidad de Argentina y de su nuevo posicionamiento defensivo. Cierto es que la reducción de la capacidad ofensiva del instrumento militar, la participación en los regímenes internacionales de control de armamentos y el establecimiento de medidas de confianza mutua y transparenciacoincidíanconlaideología neoliberal de reducir funciones del Estado. De la misma manera, aquellas iniciativas armonizaban con los consejos del realismo periférico, orientados a alinearse con los requerimientos político-estratégicos de la superpotencia, centrados en una Argentina confiable y predecible. Esto ha sido señalado como indicadores de que los designios presidenciales de los noventa fueron los determinantes de la política de defensa del momento. Pero ante esta explicación queda el interrogante: ipor qué permanecieron incólumes una vez que llegó al poder un gobierno que en materia de política exterior quiso deshacer todo lo que pudiera asociarse al menemismo? La respuesta que ofrecemos es que la base real de esas políticas estuvo constituida por ese conjunto de actores con anclaje parlamentario, no el presidencialismo.

Al leer los documentos políticos sobre defensa emitidos desde 2006 es posible ver que el kirchnerismo no solo conservó el posicionamiento defensivo sino que incluso profundizó la idea de que la política de defensa argentina había internalizado como una parte esencial la cooperación regional. Desde el decreto reglamentario de la Ley de Defensa Nacional, los documentos políticos sobre defensa -esto es, las Directivas de Política de Defensa Nacional de 2009 y su actualización de 2014, así como los Libros Blancos de 2010 y 2014incorporaron el concepto de que la política de defensa argentina tiene una doble dimensión: autónoma y cooperativa. Este posicionamiento implica que "la propia política de defensa de la Nación, su diseño de fuerzas y sus capacidades no ofensivas hacia terceros Estados, se vincula y complementa según la concepción y el posicionamiento estratégico argentino con la dimensión y los compromisos multilaterales, tanto de nivel subregional, cuanto regional y también global". 
Como hemos analizado en un trabajo anterior, a partir de 2007 las referencias a lo regional pasaron del espacio del Cono Sur y Mercosur hacia Suramérica como entorno estratégico prioritario de los esfuerzos de cooperación, que se consolidó desde la creación del CDS (Autor, 2013). Si bien los actores políticos protagonistas del consenso descrito siempre se mostraron escépticos con respecto a las posibilidades de considerar a la región andina en igualdad de posibilidades de cooperar en temas de defensa con el Cono Sur, esto no debe ser tomado como un indicador de que la entusiasta participación argentina en el CDS obedece a las inclinaciones suramericanistas de Néstor Kirchner y Cristina Fernández de Kirchner. En tanto el CDS fue delimitando que su área de actuación dejaba por fuera las cuestiones que Argentina considera pertenecientes a la seguridad interna -llegando a crear dos Consejos específicos para estas cuestiones- los actores mencionados no dudaron en manifestar su apoyo. Quienes negociaron el estatuto del CDS y sostuvieron la participación de Argentina en sus primeros años -todavía bajo la gestión de Garrédeclararon que dicha separación fue producto de la labor negociadora del país, indicador tanto de la vitalidad del consenso mínimo como del protagonismo argentino en la definición de la naturaleza del CDS.

A medida que este organismo fue consolidándose, Argentina profundizó la referencia a la cooperación regional como parte constitutiva de su identidad estratégica. Cabe citar, en este sentido, un párrafo del Libro Blanco de la Defensa Nacional 2014 -publicado en julio de 2015-donde sostiene:

La República Argentina aspira a la construcción eventual de un sistema regional que trascienda los niveles de confianza mutua ya alcanzados. Para ello se propone profundizar los vínculos con los países de la región en términos de cooperación y complementariedad militar efectiva en propósitos de interés mutuo, tales como la coparticipación en el control de espacios limítrofes comunes y la complementación de capacidades en casos de operaciones de paz u otras de apoyo, como por ejemplo la asistencia logística en actividades de investigación antártica. Consecuentemente, se tiende a asegurar las condiciones que contribuyan a garantizar el mantenimiento de la zona de paz suramericana y la previsibilidad político-estratégica regional.

De las palabras transcritas se deduce que ya no solo se manifiesta la necesidad de construir confianza y transparencia entre los países de la región, sino que se incrementa la apuesta hacia modos de cooperación que implican interoperabilidad y responsabilidades conjuntas en tareas tradicionalmente consideradas como indelegables. Ciertamente, no puede afirmarse que el resto de los socios de Argentina en el CDS comparten esta 
confianza en la regionalización de su defensa. Pero lejos de indicar un error de cálculo estratégico frente a la potencial hegemonía brasileña, fruto de un sistema político presidencialista que subestima la reflexión sobre la estrategia internacional del país, se trata, por el contrario, de la evolución esperada de ideas maduradas por actores diversos de ese sistema político.

\section{Conclusión}

Tal como recordó Donnelly (2005, p. 40), Waltz advirtió que las predicciones que hace el realismo estructural son indeterminadas porque las ciencias sociales trabajan con regularidades similares a las leyes law-like regularities- en lugar de leyes determinísticas. Existen casos en los cuales los supuestos subyacentes de una teoría se hacen presentes, pero los resultados esperados no, haciéndose necesario revisar la teoría. En otras ocasiones, el investigador no logra encontrar en un caso el resultado que predice una teoría porque dichos supuestos no están contemplados en el caso. Una tercera situación es cuando los condicionantes que una teoría predice se encuentran operando pero se ven superados por otras fuerzas que aquella teoría no contempla. Creemos que la segunda y tercera situación son de gran interés para entender por qué un análisis desde el realismo neoclásico no resulta en una explicación satisfactoria de la ausencia de una estrategia de balancing de
Argentina frente al ascenso brasileño, al menos en lo que se refiere a su política de defensa. Con respecto a la ausencia de los supuestos teóricos en este caso, sostenemos que las variables de la baja institucionalización del sistema de partidos y el nivel de delegación de la democracia no describen la realidad de lo que fue el proceso de formulación de la política de defensa argentina luego de la vuelta de la democracia. En lo que concierne a la capacidad del neorrealismo de entender dicha política, consideramos que las presiones subsistémicas vinculadas a los cambios en la distribución del poder deben ser interpretadas en función de variables ideacionales: la manera en que los actores protagonistas de esas políticas dieron sentido a la realidad pasada y presente, así como sus percepciones sobre el mediano y largo plazo.

En el contexto del debate arriba descrito, analizamos en este artículo la política de defensa argentina surgida a partir de 1983, caracterizada por el modelo defensivo y la cooperación regional. Esta política es entendida como un indicador de la renuncia a una estrategia de contrapeso con respecto a Brasil. Esto es, si Argentina hubiera decidido una orientación estratégica en función de blindarse frente a una muy potencial asimetría de poder con su vecino, no habría renunciado a una política de defensa fuerte y autónoma. Hubiera evitado, por el contrario, recortar sus gastos de defensa y hubiera conservado sus empresas de 
productos estratégicos. Ciertamente, el Brasil en el cual los civiles recuperaban el poder no parecía tan amenazante: vivía, como Argentina, un momento de endeudamiento y estancamiento económico. Sus fuerzas armadas no estaban tan desprestigiadas como las argentinas, pero habían caído en una seria crisis de identidad. Los líderes políticos y militares de ambos países habían aceptado la construcción de un inédito proceso de construcción de confianza y transparencia en materia nuclear. Lo curioso es que Argentina no solo continuó sino que incluso profundizó la política de defensa defensiva y cooperativa aun cuando el ascenso brasileño se tornaba una realidad inexpugnable. Algunos llegaron incluso a apuntar que Argentina delega parte de su defensa en la cooperación regional, algo que Brasil nunca haría. Lo que es más: quienes se inclinan por una visión realista de la política dirían que se trata de una estrategia doblemente peligrosa, ya que en anarquía internacional nunca tenemos garantías de la permanencia de intereses coincidentes en una coyuntura, o incluso que el socio decida un día engañarnos, dejando de acudir en nuestro socorro o incluso manipulando la dependencia creada a partir de la cooperación.

Ahora bien, este trabajo tuvo el propósito de evaluar el valor analítico de las explicaciones propuestas, en lugar de emitir un juicio en términos prescriptivos, respecto a la razonabilidad o no de la decisión argentina respecto a su política de defensa, tanto en su orientación como su presupuesto. En función de esto sostenemos que, a partir de un estudio detallado sobre los hechos asociados a la formulación de la política de defensa argentina, la misma debe ser entendida como producto de la negociación basada en las ideas de un conjunto de actores anclados en el Parlamento argentino y con fuertes vínculos con actores de la sociedad civil. De esta manera, relativizamos la inclusión de las variables asociadas a la inestabilidad política: la concentración del poder en el presidente y la baja institucionalización del sistema de partidos. Al proveer referentes empíricos de que el Congreso argentino funcionó como el principal emisor de normativa de defensa, como arena de la discusión sobre concepciones de defensa articulando el debate con la sociedad civil interesada en el tema y como protagonista de iniciativas de discusión regional del modelo de la seguridad cooperativa demostramos que la política de defensa argentina -parte importante de la política exterior- escapó a esas dos variables.

Un análisis detallado del caso de estudio demostró que entre 1983 y 2003, actores parlamentarios cumplieron papeles clave en la formulación de la política democrática y dieron lugar a una orientación particular para esa política, compatible con la creación de un organismo de cooperación regional en defensa. Este hecho, solamente reconocible mediante un estudio de 
caso profundo, invalida la hipótesis de que la conducta de bandwagoning de Argentina en relación con el proyecto brasileño de liderazgo pueda explicarse por la variable inestabilidad política. En lugar de haber discrecionalidad del ejecutivo la política de defensa argentina surgió del Parlamento. A partir de 2003, el Ministerio de Defensa comenzó a tomar un papel más activo, pero esto no quiere decir que se anulara lo hecho por el Congreso. Todo lo contrario, la orientación de esa política defensiva y cooperativa se cristalizó, como lo indican el hecho de la participación en el ministerio de funcionarios pertenecientes al grupo de actores analizado y las ideas plasmadas en la reglamentación de la ley de defensa, las Directiva de Política de Defensa y el Libro Blanco.

\section{REFERENCIAS}

Alves Soares, S. \& Camargo Lima, R. (2013). No limbo da dissonância: Argentina e Brasil no campo da Defesa. En Alves do Carmo, C. (et al.), Relações Internacionais: Olhares cruzados (p. 315-50). Brasília: Funag.

Burges, S. W. (2015). Revisiting consensual hegemony: Brazilian regional leadership in question. International Politics, 52 (2), 193207.

Castro, G. F. (2010). A cooperação entre Argentina e Brasil no setor de defesa: visão e ação da Argentina
(1983-2008) (Tesis inédita de maestría), Programa de posgrado en Relaciones Internacionales San Tiago Dantas (UNESP-UnicampPUC-SP), San Pablo.

Derghougassian, K. (2012). Evolución de la política de defensa. En Derghougassian, K. (ed) La defensa en el siglo XXI. Argentina y la seguridad regional (pp. 13-46). Buenos Aires: Capital Intelectual.

Diamint, R. (1997). Un producto de la posguerra fría: la cooperación en seguridad. En: Flacso-Chile, El Mercosur de la Defensa (pp. 3142). Santiago: Flacso-Chile.

Donnelly, J. (2005) Realism. En: Burchill, S. \& Reus-Smit, C. (eds) Theories of International Relations (3a. ed) (pp. 55-83). New York: Palgrave Macmillan.

Druetta, G. (1989). Herencia militar y lucha parlamentaria. Nuevo Proyecto, 5-6, 185-202.

Druetta, G., Estevez, E., López, E. \& Miguens, J. E. (1990). Defensa y democracia. Un debate entre civiles y militares. Buenos Aires: Punto Sur.

Flemes, D. \& Wehner, L. (2015). Drivers of strategic contestation: The case of South America. International Politics, 52 (2), 163-77.

García, A. L. \& Tibiletti, L. (2008). El proceso de relacionamiento estratégico argentino-chileno desde la creación del Comperseg hasta hoy: antecedentes, logros y desafíos. Informe Ser en el 2000. 
Garreta, J. (1995). La seguridad estratégica regional en la integración del Cono Sur: un caso de construcción de seguridad y paz. SER en el 2000, 8, 12-15.

Laleff Ilieff, R. (2012). Los consensos legislativos sobre las Fuerzas Armadas en la democracia argentina. Orbis. Revista Científica Ciencias Humanas, 7 (21), 20-37.

Martínez, P. (2000). La reestructuración de las fuerzas armadas y el rol del Parlamento. La experiencia argentina. Revista Fuerzas Armadas y Sociedad, 15 (1), 29-38.

Merke, F. (2015). Neither balance nor bandwagon: South American international society meets Brazil's rising power. International Politics, 52 (2), 178-92.

Miguens, J. E., Druetta, G. \& Tibiletti, L. (1994). La reubicación de las FF.AA. en la sociedad democrática. En Por 100 años de Democracia (pp. 21534). Buenos Aires: Eudeba.

Saín, M. (2010). Los votos y las botas. Estudios sobre la defensa nacional y las relaciones civil-militares en la democracia argentina. Buenos Aires: Prometeo.

Scheetz, T. (1994). Defensa noprovocativa en Argentina. Revista Fuerzas Armadas y Sociedad 9 (4) sin páginas.

Schenoni, L. (2014). Unveiling the South American Balance. Estudos Internacionais, 2 (2), 215-32.
- (2015). Towards a Realist Understanding of Security in Latin America. En: Bátor, P. \& Ondrejcsák, R. (eds), Panorama of global security environment, (pp. 457-68). Bratislava: Center for European and North Atlantic Affairs. Disponible en: https:// www.academia.edu/11969365/ Tow a rds_a_R e a I i s t Understanding_of_Security_in_Latin_America, consultado en julio de 2015.

Soprano, G. (2012). La definición de una agenda de defensa para la democracia en Argentina. Trayectorias individuales $y$ experiencias colectivas de políticos, militares y expertos civiles en el seminario y la revista Seguridad Estratégica Regional en el 2000. En: Cancino, H., de la Mora, R., de Menezes, L. M., Benito Moya, S. G. A., Miradas desde la Historia social y la Historia intelectual. América Latina en sus culturas: de los procesos independistas a la globalización. Córdoba: Centro de Estudios Históricos Prof. Carlos S.A. Segreti.

. (2013). Entre el Congreso y el ministerio. Análisis de las relaciones entre diputados y senadores nacionales, asesores legislativos, académicos y funcionarios civiles y militares en el proceso de definición de la política de defensa y militar en la Argentina (19832001). Trabajo presentado en las 
IV Jornadas de Historia Política. Universidad de la República, 8 al 10 de julio de 2013, Montevideo.

Tibiletti, L. (1995). Parlamento e relações civis-militares na transição e consolidação da democracia na Argentina (1983-1995). En: Braz Araujo, R. Reflexões sobre Estratégia: Anais do II Encontro Nacional de Estudos Estratégicos. Sao Paulo: NAIPPE/USP.

los estudios sobre Seguridad y Defensa: situación y perspectivas institucionales. Trabajo presentado en el Seminario Research and Education in Defense and Security Studies, 22-25 de mayo de 2001, Washington DC.

Ugarte, J. M. (1990). La comisión de defensa nacional: un rol casi inédito. En: Druetta, G., et al., Defensa y democracia. Un debate entre civiles y militares (pp. 25364). Buenos Aires: Punto Sur.
- (2004). Los conceptos jurídicos y políticos de la seguridad y la defensa: un análisis orientado a América Latina. Buenos Aires: Plus Ultra.

Verbitsky, H. (2015). Zona gris. Página 12, septiembre 13 de 2015, sec. El País. Disponible en: http:// www.pagina12.com.ar/diario/ elpais/1-281574-2015-09-13. html, consultado en julio de 2015.

Vitelli, M. (2011). El interés nacional como una construcción social: la política de defensa argentina en el período 2005-2009. En Miranda, R. (ed) Política exterior. Conceptos y enfoques en torno a Argentina (pp. 113-49). Rosario: Ediciones PIA.

. (2015). Ideas y política exterior: la comunidad epistémica de defensa argentina y su rol en la cooperación regional. Relaciones Internacionales (UNLP), 24 (48), 33-57. 